\title{
MISTURA DE LOTES DE SEMENTES DE MILHO DE DIFERENTES IDADES. 1. EFEITOS SOBRE A QUALIDADE FISIOLOGICA DAS SEMENTES*
}

S.M. Cicero**

RESUMO: O presente trabalho teve como objetivo estudar os efeitos da mistura de sementes de milho produzidas em duas safras consecutivas (sementes com aproximadamente um ano de idade e sementes novas) sobre sua qualidade fisiológica. Para tanto, foram utilizadas se mentes de 4 cultivares produzidas nos anos agrícolas de 1984/85 e 1985/86; inicialmente, o material mais velho foi armazenado sob duas condições (ambiente não controlado e cámara seca) por um período de cerca de 6,5 meses, quando se procedeu, então, a mistura daqueles materiais, nas proporções de $10 \%$, $15 \%$ e $20 \%$, com semen tes mais novas (safra 1985/86); foram testados tambem os materiais constituídos por $100 \%$ de sementes produzi das na primeira safra armazenadas nas duas condiçōes $\vec{j} \vec{a}$ referidas e aquele constituido por $100 \%$ de sementes produzidas na ültima safra. Conclui-se que, nas condições do presente trabalho, a mistura de sementes de milho de duas safras subsequentes pode ser uma alternativa viável para o aproveitamento de sobras não comercializadas, pois a mistura das sementes mais velhas numa proporção de até $20 \%$ não afetou a germinação do material resultante; por outro lado, isto também ocorreu com o vigor quando aquela proporção era de até $10 \%$.

* Trabalho parcialmente financiado pela FINEP.

** Departamento de Agricultura da E.S.A."Luiz de Quei roz" da Universidade de São Paulo - 13.400 - Piracicaba, SP. Bolsista do CNPq. 
Termos para indexação: mistura de sementes, idade de sementes, germinação, vigor.

\section{BLENDING OF CORN SEED LOTS OF DIFFERENT AGES. 1. EFFECTS ON SEED PHYSIOLOGICAL QUALITY}

ABSTRACT: The objective of this work was to study blending of corn seeds obtained in two consecutive cropping seasons (one year old seeds and new seeds) as to its effect on seed physiological quality. Seeds obtained from 4 cultivars grown in the 1984/85 and 1985/86 cropping seasons were utilized. The older seeds were initially stored under two conditions (non controlled environment and dry chamber) for a period of about 6,5 months. Blending was then done to obtain three lots with $10 \%, 15 \%$ and $20 \%$ old seeds, respectively. Lots from the two growing seasons were also tested separately. Performance of the various seed lots was evaluated by means of germination and vigor tests. The results indicated that corn seeds obtained from two consecutive cropping seasons can be used as a valid alternative for the utilization of commercial surplus for it was found that up to $20 \%$ of older seeds had no significant effect on total seed germination where as seed vigor was not affected by as much as $10 \%$ of older seeds. vigor.

Index terms: Seed blending, seed age,germination,

\section{INTRODUCAOO}

A utilização de sementes de boa qualidade por par te dos agricultores é um fator de muita importāncia para o sucesso do estabelecimento da cultura no campo e 
que poderá se refletir na produtividade.

Com relação à cultura do milho, tēm sido coloca das no mercado sementes de alta qualidade, produzidas por empresas particulares e por órgãos püblicos. Entre tanto, no caso da produção por empresas privadas, há umá particularidade pouco encontrada para a maioria das outras grandes culturas: as sementes são tratadas com mistura de inseticidas e fungicidas, tornando-se impróprias ao consumo alimentar. Assim, no caso de sobras, säo utilizadas atualmente as alternativas de destruição ou armazenamento até a safra seguinte, quando poderão ser comercializadas após reanálise. Esta segunda opção, contudo, encontra dificuldades na aceitação do pro duto pelo comprador.

Evidentemente, isto representa não apenas um possível prejuízo financeiro às companhias produtoras de sementes de milho mas também um provável desperdicio de sementes de boa qualidade. Desta forma, procedimentos que alterassem este panorama, sem afetar a qualidade do produto oferecido aos agricultores, seriam de grande interesse.

Assim, o presente trabalho teve o objetivo de estudar os efeitos da mistura de sementes de milho produzidas em duas safras subsequentes sobre a qualidade fisiologica das mesmas.

As pesquisas relacionadas à mistura de sementes de diferentes qualidades e de diferentes idades não são numerosas. VAUGHAN et alii (1972) relatou que a industria de sementes tem se confrontado, por um longo perío do de tempo, com o problema da desuniformidade das amos tras retiradas das embalagens que constituem um lote de sementes e que com a evolução na àrea de tecnologia de sementes, o problema tem se acentuado e com isto, o interesse por métodos e técnicas de mistura de sementes tem se renovado.

DELOUCHE (1975) definiu a mistura entre lotes como sendo caracterizada pela mistura de sementes e/ou particulas que compõem duas ou mais porções distintas 
de lotes de sementes; relatou, ainda, que quando as por ções ou partículas são razoavelmente similares, a mistu ra entre lotes não é difícil. Citou como exemplo a mis tura de sementes com baixa porcentagem de germinação com outras de alta porcentagem, do mesmo cultivar; segundo este autor, esta é uma prätica comum e é razoa velmente fácil, pois neste caso as partículas não são apenas semelhantes, elas são idénticas, exceto pelo poder germinativo, o qual não tem efeito sobre a mistura.

Para que se possa proceder à mistura de lotes de sementes, hä necessidade de um mecanismo de alimentação que permita a mistura nas proporçóes corretas através de um fluxo comum de sementes e, complementando, outro mecanismo que permita a mistura de tal maneira que a porção resultante seja a mais homogênea possível (DELOU CHE, 1975); desta forma, segundo o referido autor, $\bar{a}$ mistura entre lotes pode ser realizada num fluxo continuo, não importando o tamanho do lote.

Alguns equipamentos, visando a mistura de sementes de algumas espécies, foram testados por VAUGHAN et alii (1972); verificaram que, no caso da mistura de sementes de trigo germinàveis e não germináveis, a porção resultante foi uniforme (verificado através de testes de germinação e de tetrazōlio) e assim permaneceu após o acondicionamento das sementes.

Por outro 1ado, KAHRE (1971) relatou que na Suécia foram misturadas sementes de värias espécies que apresentavam germinação em diferentes niveis, resultando em 516 lotes; apenas 26 desses lotes ficaram abaixo dos padrões estabelecidos para fins de comercializaça e que, portanto, o resultado foi satisfatório.

Especificamente com a cultura do milho, foram encontrados na literatura consultada apenas quatro trabalhos sobre mistura de sementes. Dois deles foram condu zidos por CAMPOS (1979 e 1980); no primeiro trabalho, realizado em 1979, foram utilizadas sementes dos hibridos comerciais AG $162 / 5$ e HMD 7974 , produzidas nas safras de $1976 / 77$ e $1977 / 78$ e testadas as misturas das se 
mentes nas proporções de $10 \%$ e $26 \%$ da semente mais ve lha com $90 \%$ e $74 \%$, respectivamente, das sementes mais novas, comparando-as com os materiais constituidos por $100 \%$ de sementes de cada uma das duas safras; foi observado que houve tendéncia para um comportamento mais fraco à medida que se aumentava a proporção de sementes da primeira safra (sementes mais velhas). No segundo experimento, CAMPOS (1980) obteve resultados identicos ao primeiro, utilizando os mesmos híbridos produzidos nas safras 1976/77, 1977/78 e 1978/79 em dois anos de experimentação.

Utilizando sementes de milho híbrido, do cultivar C111, BORGES (1983) estudou os efeitos da mistura de lotes de diferentes qualidades sobre o desempenho das sementes e verificou que é viável o aproveitamento de lotes de sementes que seriam descartados, em razão de apresentarem porcentagem de germinação abaixo dos padrões de sementes para fins de comercialização. Esse autor relatou que a mistura entre lotes de sementes com níveis de germinação de $51 \%$ e $88 \%$ até a proporção de $10 \%$ do lote com germinação inferior, manteve o padrão de germinação exigido para o Estado de Minas Gerais ( $85 \%)$ e que para satisfazer as condiçöes do padrão nacional $(60 \%)$ é possível utilizar até $50 \%$ de sementes de germinação inferior ( $51 \%$ ) para a composição da mistura; tambēm foi observado que o maior nümero de sementes de qualidade inferior, reduziu proporcionalmente o vigor do lote.

Mais recentemente, CICERO (1987), trabalhando com os cultivares AG162, AG401, Contimax 133 e C115 e estudando as misturas de $10 \%, 15 \%$ e $20 \%$ de sementes produzidas na safra de $1983 / 84$ com sementes da safra $1984 / 85$ concluiu que a mistura de sementes de milho de duas safras subsequentes pode ser uma alternativa viavel para o aproveitamento de sobras não comercializadas, desde que as sementes mais velhas não participem numa proporção superior a $10 \%$ na mistura; nesta situação o autor não observou redução na qualidade fisiológica das sementes. 


\section{MATERIAL E METODOS}

o trabalho foi conduzido no Laboratório de Análise de Sementes do Departamento de Agricultura da E.S.A. "Luiz de Queiroz", Universidade de São Paulo (LAS/LAG/ ESALQ/USP), em Piracicaba, SP.

Foram utilizados quatro cultivares (híbridos duplos comerciais AG162, AG401, Contimax 133 e C115) e que serão designados daqui por diante como A, B, C e D.

Inicialmente foram obtidos, em dezembro de 1985, dois sacos de sementes de $40 \mathrm{~kg}$ cada um, para cada cultivar, produzidas na safra 1984/85 e que representaram a "sobra" de sementes da referida safra (primeira safra).

As sementes dos cultivares A, B e D eram classifi cadas por largura (peneira 22/64") e tinham sido tratadas com uma mistura do fungicida captan 75 e os inseticidas deltametrina $2,5 \%$ + butóxido de piperonila $10 \%$ e malathion $100 E$ enquanto o cultivar C tinha suas semen tes classificadas como peneira $20 / 64 "$ e tratadas com uma mistura do fungicida PCMB $24 \%$ + etridiozol $6 \%$ e os inseticidas malathion $100 \mathrm{E}$ e perimifós metílico $50 \%$.

Com a finalidade de avaliar a qualidade inicial do referido material, as sementes provenientes dos dois sacos de cada cultivar, foram misturadas e homogeneizadas e retiraram-se amostras com as quais foram conduzidos testes de germinação, primeira contagem de germinação, envelhecimento rápido, frio, condutividade elétri$c a$, exame de sementes infestadas e determinação do grau de umidade. Os dados obtidos podem ser observados na Tabela 1 .

Após a retirada das amostras para a avaliação da qualidade inicial, as sementes de cada cultivar foram divididas em duas partes iguais $(40 \mathrm{~kg})$, colocadas de volta nas embalagens originais (sacos de papel multifoliado) e armazenadas em dois ambientes: uma das partes em condições de ambiente de laboratório do LAG/ESALQ e 
Tabela 1. Avaliação da qualidade inicial das sementes, dos quatro cultivares, produzidas na safra $1984 / 85$.

\begin{tabular}{lllllrll}
\hline $\begin{array}{llll}\text { Culti- } \\
\text { vares }\end{array}$ & $\begin{array}{l}\text { TG } \\
(\%)\end{array}$ & $\begin{array}{l}\text { PCG } \\
(\%)\end{array}$ & $\begin{array}{c}\text { ER } \\
(\%)\end{array}$ & $\begin{array}{l}\text { TF } \\
(\%)\end{array}$ & $\begin{array}{c}\text { CE } \\
(\mu \text { mhos/g) }\end{array}$ & $\begin{array}{l}\text { ESI } \\
(\%)\end{array}$ & $\begin{array}{l}\text { DGU* } \\
(\%)\end{array}$ \\
\hline A & 96 & 84 & 96 & 94 & 9,68 & 1,5 & 9,4 \\
B & 94 & 80 & 96 & 94 & 12,52 & 0,0 & 9,8 \\
C & 88 & 74 & 36 & 86 & 11,63 & 0,0 & 9,5 \\
D & 98 & 84 & 97 & 98 & 7,44 & 0,5 & 9,2
\end{tabular}

$* \mathrm{TG}=$ Teste de germinação. PCG = Primeira contagem de germinação. $\mathrm{ER}=$ Envelhecimento räpido. $\mathrm{TF}=$ Teste de frio. $C E=$ Condutividade elétrica. ESI $=$ Exame de sementes infestadas. DGU = Determinação do grau de umidade.

que passa a ser designada de $L A B / 85$ e a outra em câmara seca do LAS/LAG/ESALQ, a $35 \%$ de umidade relativa do ar e temperatura média de $23^{\circ} \mathrm{C}$, a qual foi designada de $\mathrm{CS} / 85$. Ambos os materiais permaneceram nas referidas condições por um periodo de aproximadamente 6,5 meses $(20 / 12 / 1985$ a $31 / 07 / 1986)$. Ao final desse período, foram conduzidos testes de germinação, primeira contagem de germinação, envelhecimento rápido, frio, condutivida de elétrica, exame de sementes infestadas e determina ção do grau de umidade, com a finalidade de caracteri zar novamente o material que seria utilizado na mistura com as sementes da safra 1985/86. Os dados obtidos podem ser observados na Tabela 2 .

Em junho de 1986 foram obtidos mais dois sacos de sementes ( $40 \mathrm{~kg}$ cada um), para cada cultivar, produzi das na safra 1985/86 e que representaram as sementes da ültima safra, ou seja, aquelas que seriam normalmente comercializadas no ano de 1986. As sementes desta sa- 
Tabela 2. Avaliação da qualidade das sementes, dos quatros cultivares, após o periodo inicial de ar mazenamento $(20 / 12 / 1985$ a $31 / 07 / 1986)$ em condiçōes normais de ambiente de laboratório $(\mathrm{LAB} / 85)$ e de cāmara seca (CS/85).

\begin{tabular}{|c|c|c|c|c|c|c|c|}
\hline $\begin{array}{l}\text { Cultivares/ } \\
\text { Ambientes de } \\
\text { Armazenamento }\end{array}$ & $\begin{array}{l}\text { TG } \\
(\%)\end{array}$ & $\begin{array}{l}\text { PCG } \\
(\%)\end{array}$ & $\begin{array}{r}\text { ER } \\
(\%)\end{array}$ & $\begin{array}{r}\mathrm{TF} \\
(\%)\end{array}$ & $\begin{array}{c}\mathrm{CE} \\
(\mu \mathrm{mhos} / \mathrm{g})\end{array}$ & $\begin{array}{l}\text { ESI } \\
(\%)\end{array}$ & $\begin{array}{l}\text { DGU* } \\
(\%)\end{array}$ \\
\hline A LAB $/ 85$ & 96 & 93 & 84 & 89 & 11,34 & 0,3 & 10,9 \\
\hline A CS/85 & 95 & 93 & 94 & 94 & 9,29 & 0,5 & 9,4 \\
\hline B LAB $/ 85$ & 90 & 90 & 84 & 85 & 15,45 & 0,3 & 12,1 \\
\hline B CS/85 & 95 & 93 & 89 & 84 & 15,82 & 0,8 & 10,5 \\
\hline C LAB/85 & 77 & 74 & 09 & 26 & 14,99 & 0,3 & 12,0 \\
\hline C $\mathrm{CS} / 85$ & 86 & 86 & 14 & 55 & 12,92 & 0,0 & 10,4 \\
\hline D LAB / 85 & 96 & 96 & 93 & 93 & 9,67 & 1,3 & 10,5 \\
\hline D CS/85 & 97 & 96 & 96 & 97 & 8,01 & 2,0 & 9,3 \\
\hline
\end{tabular}

* TG $=$ Teste de germinação. PCG = Primeira contagem de germinação. $\mathrm{ER}=$ Envelhecimento rápido. $\mathrm{TF}=$ Teste de frio. $C E=$ Condutividade elétrica. $E S I=$ Exame de sementes infestadas. DGU = Determinação do grau de umidade.

fra apresentavam as mesmas caracteristicas quanto à classificação pela largura, daquelas obtidas na safra $1984 / 85$ e também haviam sido tratadas com os mesmos pro dutos.

Os dois sacos de sementes de cada cultivar foram também misturados e homogeneizados para que, posteriormente, fossem retiradas amostras visando a avaliação da qualidade inicial do referido material; para tanto foram conduzidos os mesmos testes que foram utilizados com as sementes adquiridas em dezembro de 1985 (safra 1984/85). Os dados obtidos podem ser observados na Tabela 3 . 
Tabela 3. Avaliação da qualidade inicial das sementes, dos quatro cultivares, produzidas na safra $1985 / 86$.

\begin{tabular}{cccccccc}
\hline $\begin{array}{cccc}\text { Culti- } \\
\text { vares }\end{array}$ & $\begin{array}{c}\text { TG } \\
(\%)\end{array}$ & $\begin{array}{c}\text { PCG } \\
(\%)\end{array}$ & $\begin{array}{c}\text { ER } \\
(\%)\end{array}$ & $\begin{array}{c}\text { TF } \\
(\%)\end{array}$ & $\begin{array}{c}\text { CE } \\
(\mu \text { mhos } / g)\end{array}$ & $\begin{array}{r}\text { ESI } \\
(\%)\end{array}$ & $\begin{array}{l}\text { DGU* } \\
(\%)\end{array}$ \\
\hline A & 98 & 97 & 95 & 96 & 9,13 & 3,0 & 11,3 \\
B & 94 & 94 & 97 & 96 & 10,30 & 0,3 & 12,0 \\
C & 97 & 97 & 97 & 98 & 8,45 & 0,3 & 11,9 \\
D & 98 & 98 & 99 & 99 & 6,57 & 1,0 & 9,8 \\
\hline
\end{tabular}

$* \mathrm{TG}=$ Teste de germinação. $\quad$ PCG = Primeira contagem de germinação. $E R=$ Envelhecimento rápido. $T F=$ Teste de frio. $C E=$ Condutividade eletrica. ESI = Exame de sementes infestadas. $D G U=$ Determinação do grau de umidade.

A mistura das sementes produzidas nas duas safras foi realizada com base no peso de mil sementes; assim, calculava-se o peso de cada material que deveria ser misturado ao outro, conforme as proporçóes desejadas, ou sejam $10 \%, 15 \%$ e $20 \%$ em peso das sementes da safra 1984/85 com, respectivamente, $90 \%$, $85 \%$ e $80 \%$ em peso das sementes produzidas na safra 1985/86. Desta forma, em $01 / 07 / 1986$, foram constituidos os tratamentos para cada um dos cultivares em estudo (Tabela 4).

Após a mistura e a homogeneização, cada uma das amostras (parcelas) foi embalada em sacos de papel multifoliado, com capacidade de $5 \mathrm{~kg}$, e armazenada em condições normais de ambiente do LAS/LAG, onde permaneceu até o final do período experimental (07/11/1986).

A qualidade das sementes dos diferentes tratamentos foi avaliada em duas épocas (julho/agosto e outubro/novembro de 1986, utilizando-se os seguintes testes: 
Tabela 4. Constituição dos tratamentos para cada um dos cultivares.

Tratamentos

Composição das misturas por safra/condição de armazenamento (\%)

$\begin{array}{ccc}84 / 85 & 85 / 86 & 84 / 85 \\ (\mathrm{LAB} / 85) & (\mathrm{LAB} / 86) & (\mathrm{CS} / 85)\end{array}$

1. $100 \% \mathrm{LAB} / 85$

2. $100 \% \mathrm{LAB} / 86$

3. $100 \% \mathrm{CS} / 85$

4. $10 \% \mathrm{LAB} / 85+90 \% \mathrm{LAB} / 86$

5. $15 \% \mathrm{LAB} / 85+85 \% \mathrm{LAB} / 86$

6. $20 \% \mathrm{LAB} / 85+80 \% \mathrm{LAB} / 86$

7. $10 \% \mathrm{CS} / 85+90 \% \mathrm{LAB} / 86$

8. $15 \% \mathrm{CS} / 85+85 \% \mathrm{LAB} / 86$

9. $20 \% \mathrm{CS} / 85+80 \% \mathrm{LAB} / 86$

$\begin{array}{ccc}100 & - & - \\ - & 100 & - \\ - & - & 100 \\ 10 & 90 & - \\ 15 & 85 & - \\ 20 & 80 & - \\ - & 90 & 10 \\ - & 85 & 15 \\ - & 80 & 20\end{array}$

a) Teste de germinação, conduzido com 2 subamos tras de 50 sementes para cada repetição dos tratamentos e de acordo com as demais instruções contidas nas Ragras para Anālise de Sementes (BRASIL, Ministério da Agricultura, 1980).

b) Primeira contagem de germinação, realizada jun tamente com o teste de germinação, em técnica semelhante à descrita por MARCOS FILHo et aliz (1987).

c) Envelhecimento rápido, conduzido com 2 subamos tras de 50 sementes para cada repetiça dos tratamentos, utilizando o método "gerbox", conforme descrição feita por MARCOS FILHO et alii (1987).

d) Teste de frio, conduzido com uma amostra de 100 sementes para cada repetição dos tratamentos. A se meadura era realizada em caixas de plästico contendo uma mistura de $2 / 3$ de areia com $1 / 3$ de solo proveniente de ärea cultivada, há vários anos, com milho, para de- 
pois adicionar-se ägua atẻ a capacidade de campo. A se guir, as caixas eram levadas para uma càmara reguladā a $13^{\circ} \mathrm{C}$ onde permaneciam por um periodo de 168 horas;ven cido este periodo as caixas eram levadas para uma casa de vegetaçào com controle automático de temperatura $\left( \pm 30^{\circ} \mathrm{C}\right)$. A avaliação do teste era realizada 7 dias após a permanéncia na casa de vegetação, computando - se como plāntulas emergidas aquelas que tivessem, no mínimo, $5 \mathrm{~cm}$ de altura.

e) Teste de condutividade eletrica, conduzido com uma amostra de 25 sementes para cada repetiça dos tratamentos, conforme metodologia descrita por MARCOS FILHO et ali $(1987)$.

f) Exame de sementes infestadas, realizado com uma amostra de 100 sementes para cada repetição dos tra tamentos e de acordo com as demais instruções contidas nas Regras para Anälise de Sementes (BRASIL, Ministério da Agricultura, 1980).

g) Determinação do grau de umidade, pelo método da estufa, a $105^{\circ} \mathrm{C}$ durante 24 horas, conforme metodologia indicada pelas Regras para Análise de Sementes (BRA SIL, Ministērio da Agricultura, 1980).

A anàlise dos dados foi realizada separadamente para cada cultivar, utilizando-se o delineamento inteiramente casualizado, com 4 repetições, sendo as anālises de variāncia realizadas separadamente para cada épo ca. Para tanto, os dados correspondentes às porcenta gens de germinação, primeira contagem de germinação, en velhecimento räpido e teste de frio foram transformados em arc sen $\sqrt{\text { porcentagem/100 }}$ enquanto que os de condutividade elétrica não sofreram transformações.

\section{RESULTADOS E DISCUSSAOO}

Nas Tabelas 5 e 6 são apresentadas as mëdias obti das para os tratamentos nos testes de germinação, primeira contagem de germinação, envelhecimento rápido, 


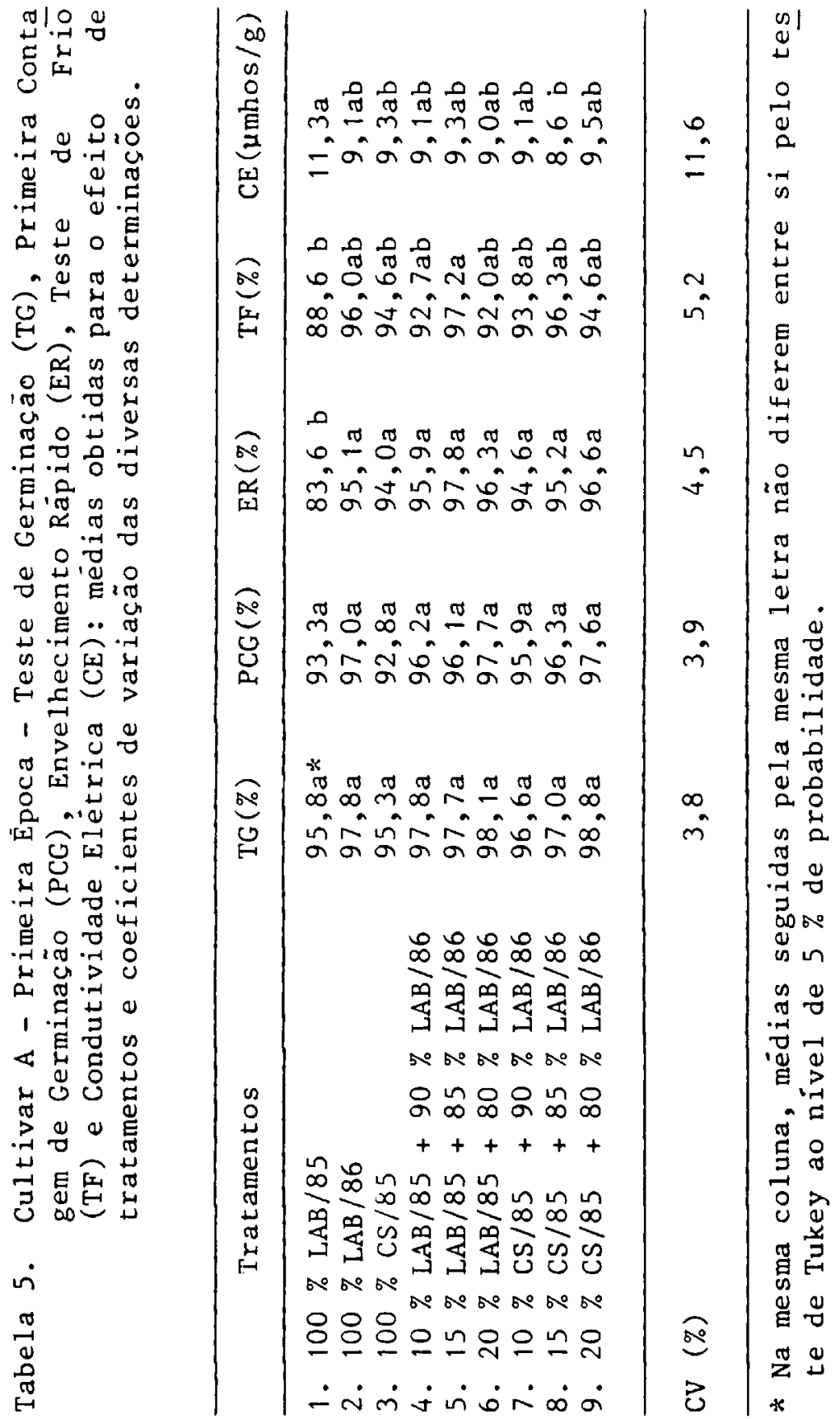




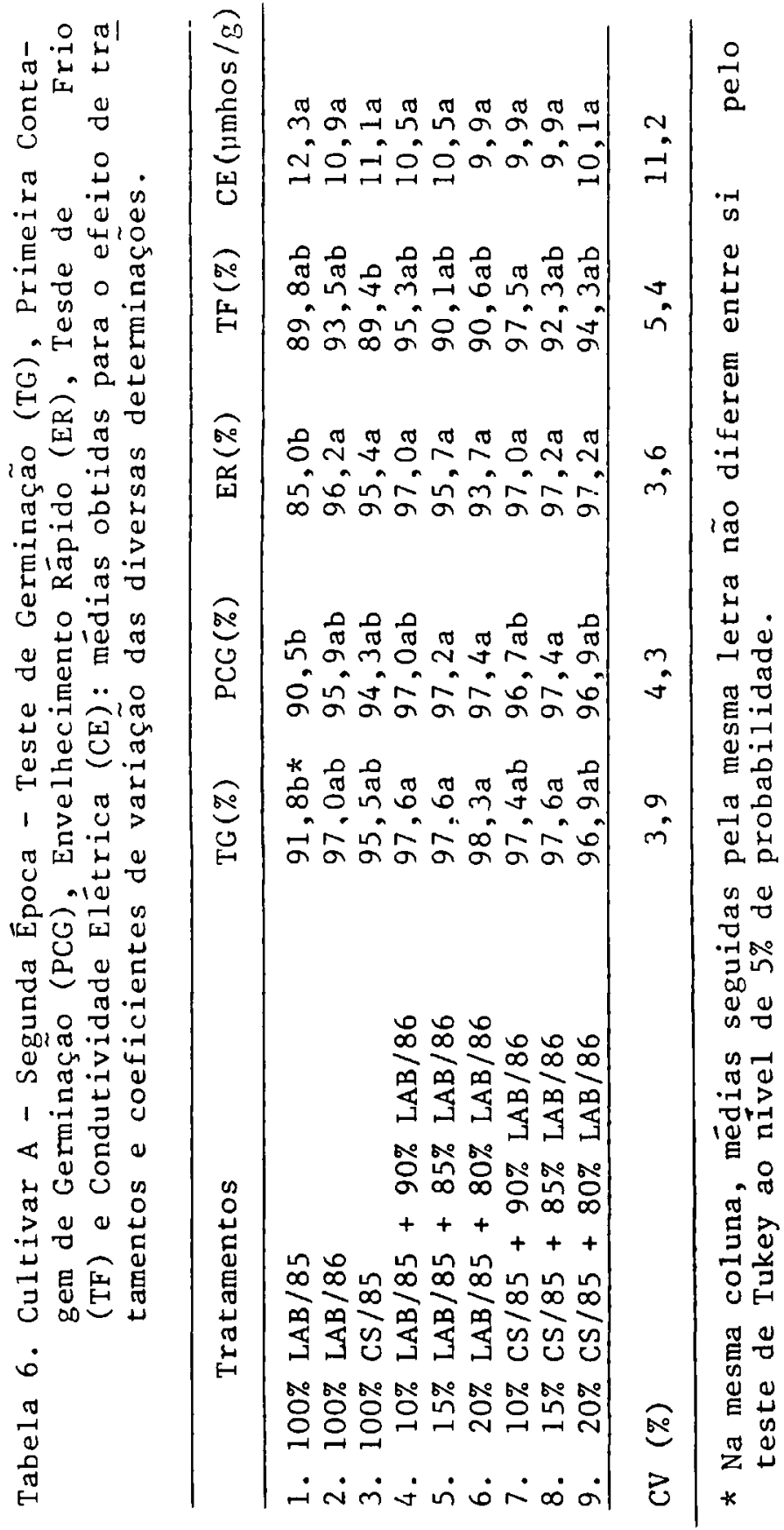


frio e condutividade elétrica, conduzidos respectivamente na primeira e segunda épocas para o cultivar A. Em resumo, para este cultivar, observou-se que a germinação e o vigor do material resultante da mistura de sementes das duas safras não se diferenciou estatistivamente do material constituído exclusivamente por sementes da ülti ma safra (sementes novas).

Os dados referentes ao exame de sementes infestadas e determinação do grau de umidade das sementes não foram analisados estatisticamente, para o cultivar A, o nivel de infestação manteve-se baixo (menor ou igual a $3 \%$ ) para todos os tratamentos nas duas épocas enquanto que o grau de umidade variou de $9,4 \%$ a $11,6 \%$ na primeira época e de $9,9 \%$ a $11,1 \%$ na segunda época.

Nas Tabelas 7 e 8 são apresentadas as médias obtidas para os tratamentos nos diferentes testes, conduzidos respectivamente na primeira e segunda épocas para o cultivar B. Em resumo, para este cultivar, observou - se que a germinação do material resultante da mistura de se mentes das duas safras não se diferenciou estatisticamen te do material constituido exclusivamente por sementes da ültima safra (sementes novas). Tal fato também foi ob; servado na maioria dos testes de vi yor empregados, umá vez que apenas para o teste de condutividade elétrica, conduzido na segunda época, houve comportamento inferior para os tratamentos 4 e 5 (misturas de $10 \%$ e $15 \%$, respec tivamente, de sementes da safra $1984 / 85$ armazenadas e $\bar{m}$ laboratório com $90 \%$ e $85 \%$ de sementes da safra 1985/86) e tratamento 9 (mistura de $20 \%$ de sementes da safra $1984 /$ 85 armazenadas em câmara seca com $80 \%$ de smentes da safra $1985 / 86$ ).

Com relação à porcentagem de sementes infestadas, observou-se para o cultivar B niveis de no máximo $0,8 \%$ para todos os tratamentos nas duas épocas de condução dos testes.Por outro 1 ado, o teor de ägua das sementes va riou de $10,5 \%$ a $12,3 \%$ na primeira época e de $9,4 \%$ a $10,9 \%$ na segunda época.

Nas Tabelas 9 e 10 são apresentadas as médias obti 


\begin{tabular}{|c|c|c|c|c|}
\hline 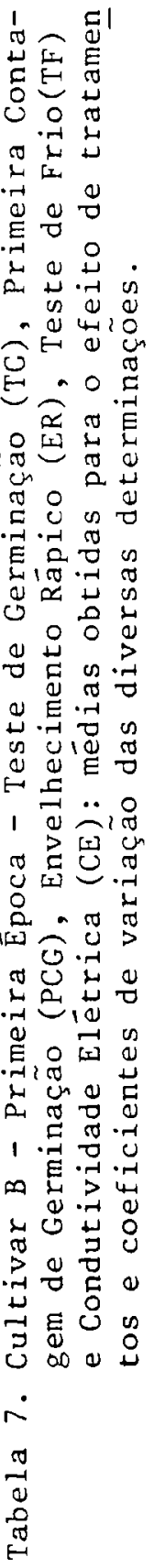 & 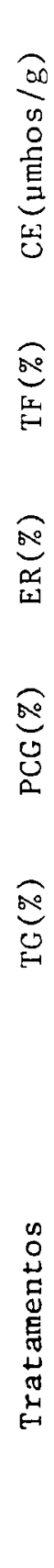 & 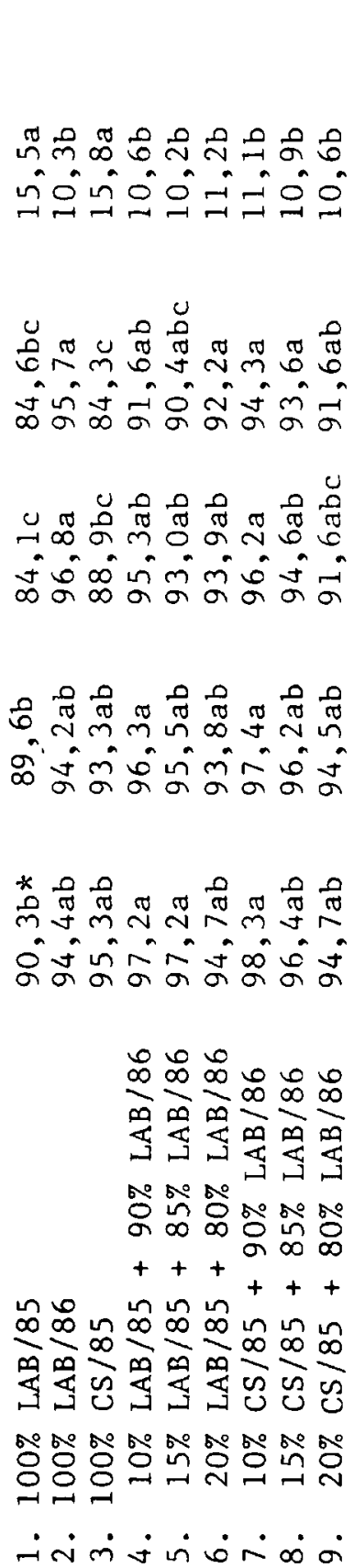 & $\begin{array}{l}80 \\
3\end{array}$ & 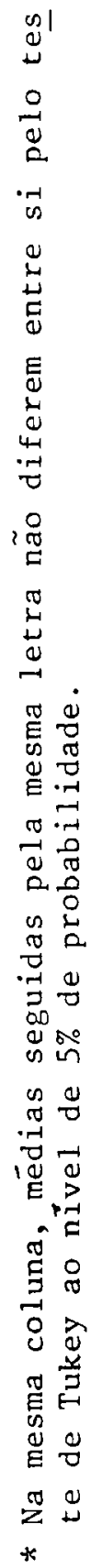 \\
\hline
\end{tabular}




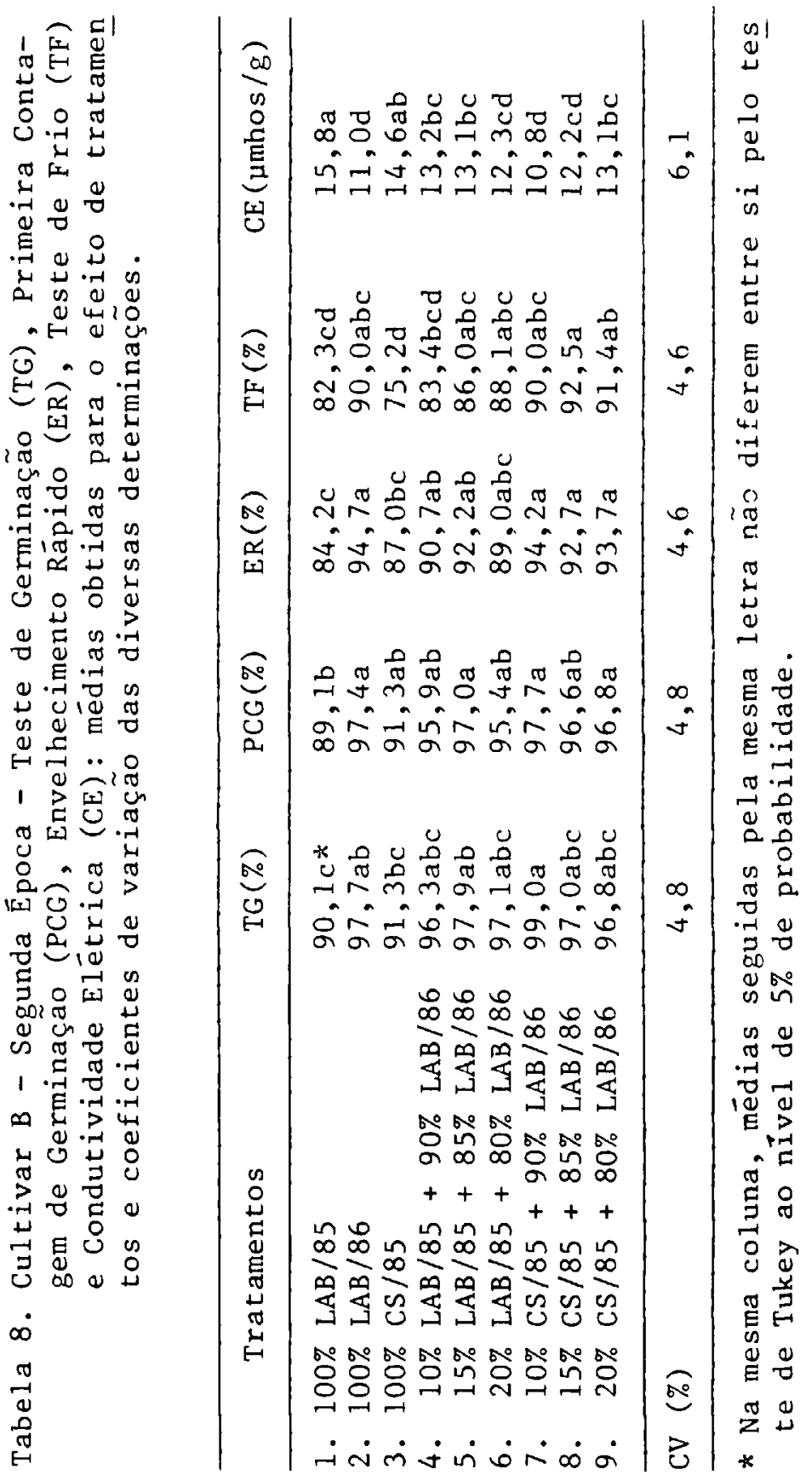




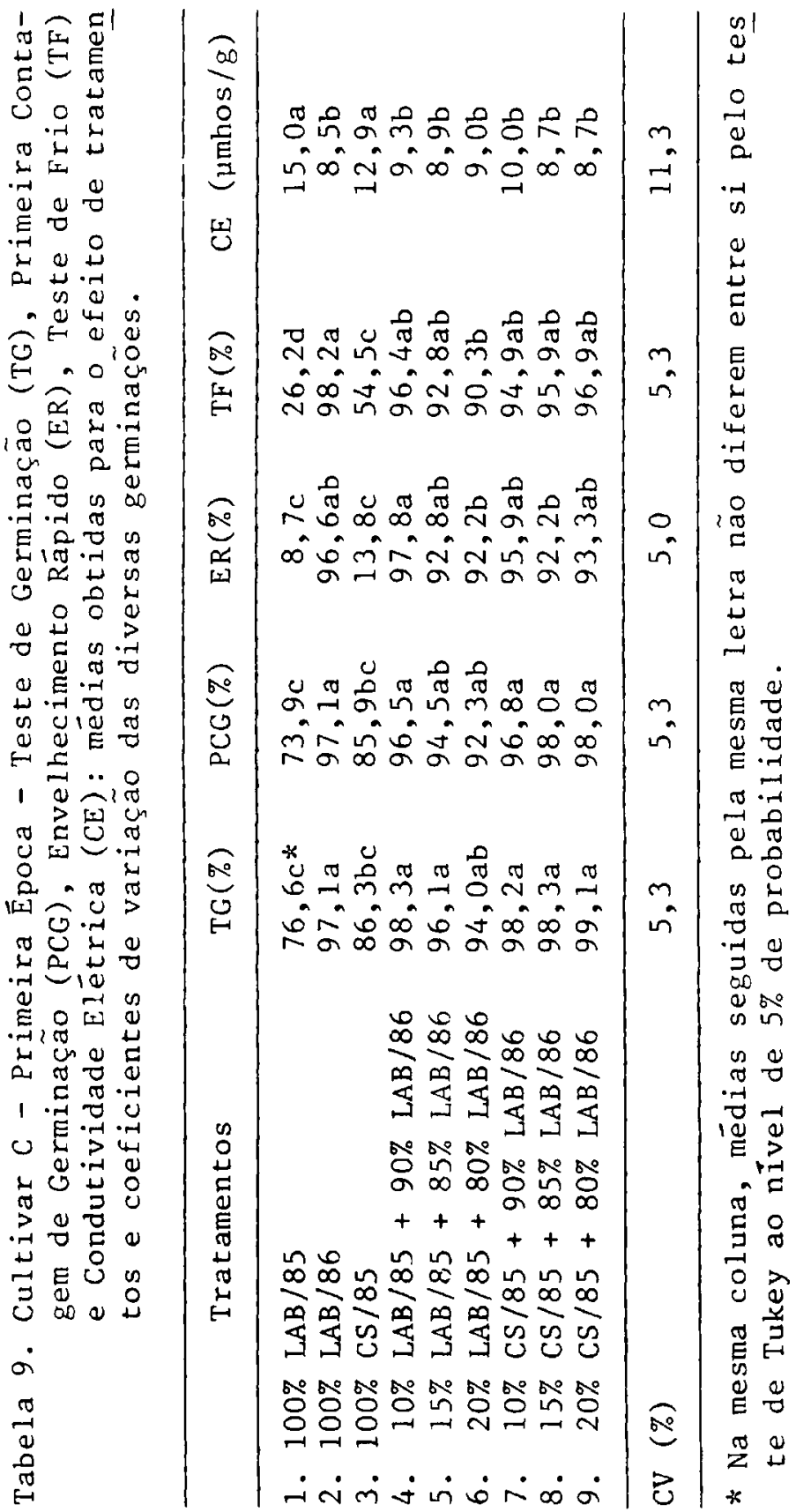




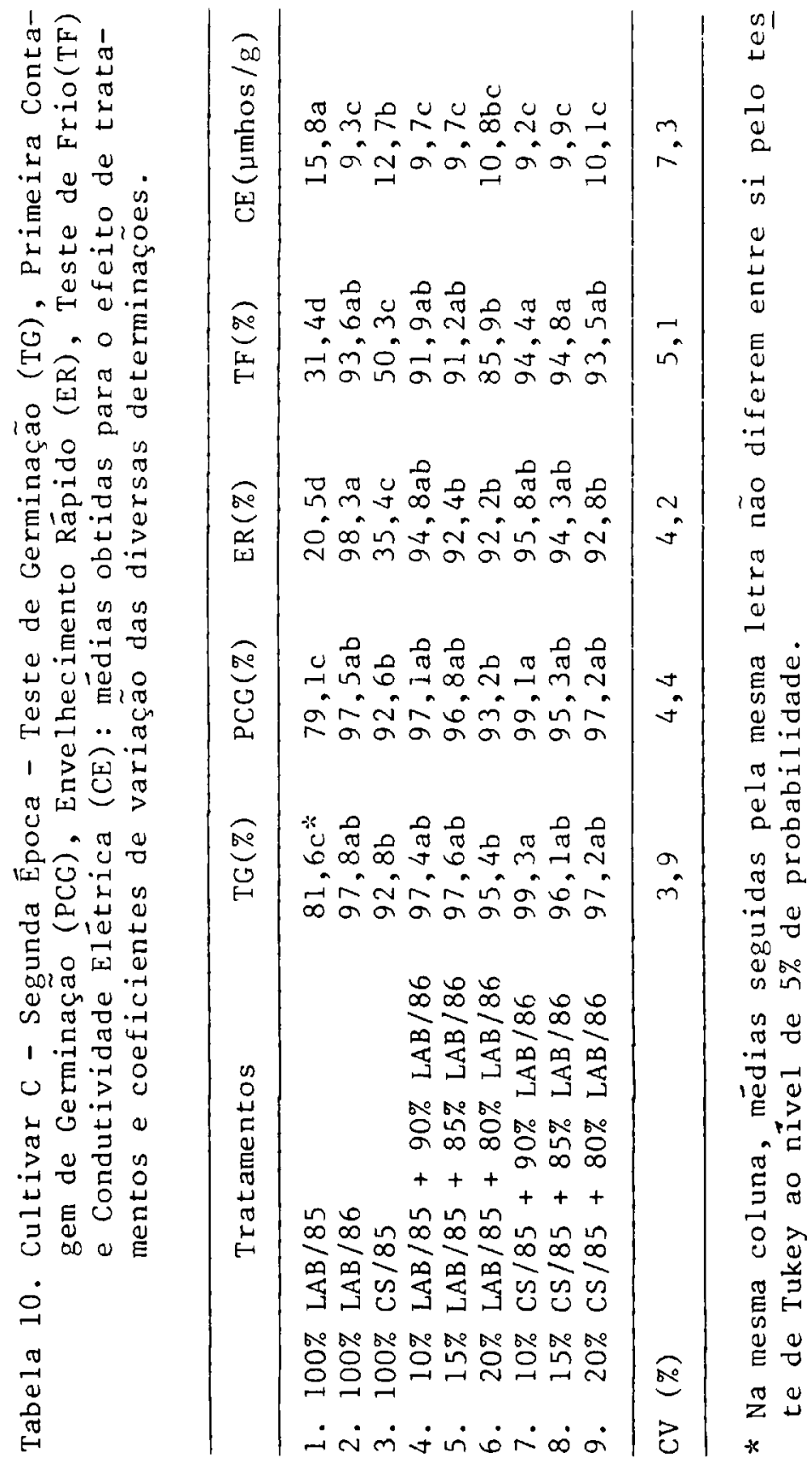


das para os tratamentos nos testes de germinação e de vigor, conduzidos respectivamente na primeira e segunda épocas para o cultivar $C$. Em resumo, para este . cultivar, observou-se que a germinação do material resultante da mistura de sementes das duas safras não se diferenciou estatisticamente do material constituído exclusivamen te por sementes da ültima safra (sementes novas). Fato semelhante tambëm foi observado na maioria dos testes de vigor empregados, pois houve desempenho inferior apenas para o tratamento $20 \% \mathrm{LAB} / 85+80 \% \mathrm{LAB} / 86$ no teste de frio conduzido na primeira época e para os tratamentos 5 e 6 (misturas de $15 \%$ e $20 \%$ de sementes da safra $1984 / 85$ armazenadas em laboratório com, respectivamente, $85 \%$ e $80 \%$ de sementes da safra $1985 / 86$ ) e o tratamento $20 \%$ CS/ $85+80 \%$ LAB/86 no teste de envelhecimento rápido conduzido na segunda época.

No exame de sementes infestadas, observou-se para o cultivar $C$ níveis de no máximo $0,5 \%$ para todos os tratamentos nas duas épocas de condução dos testes. O grau de umidade das sementes, por sua vez, variou de $10,4 \%$ a $12,00 \%$ na primeira época e de $9,6 \%$ a $10,9 \%$ na segunda época.

Nas Tabelas 11 e 12 são apresentadas as médias ob tidas para os tratamentos nos testes de germinação e de vigor, conduzidos respectivamente na primeira e segunda épocas para o cultivar D. Em resumo, para este. cultivar, observou-se que a germinação e o vigor do material resultante da mistura de sementes das duas safras não se diferenciou estatisticamente do material constituído exclusivamente por sementes da última safra (sementes novas).

Com relação à porcentagem de sementes infestadas, observou-se para o cultivar D níveis de no máximo $2,0 \%$ para todos os tratamentos nas duas épocas da condução dos testes. Por outro 1ado, o teor de água das sementes variou de $9,3 \%$ a $10,6 \%$ na primeira época e de $9,3 \%$ a $10,3 \%$ na segunda época.

o exame das Tabelas de 5 a 12 permite

verificar 


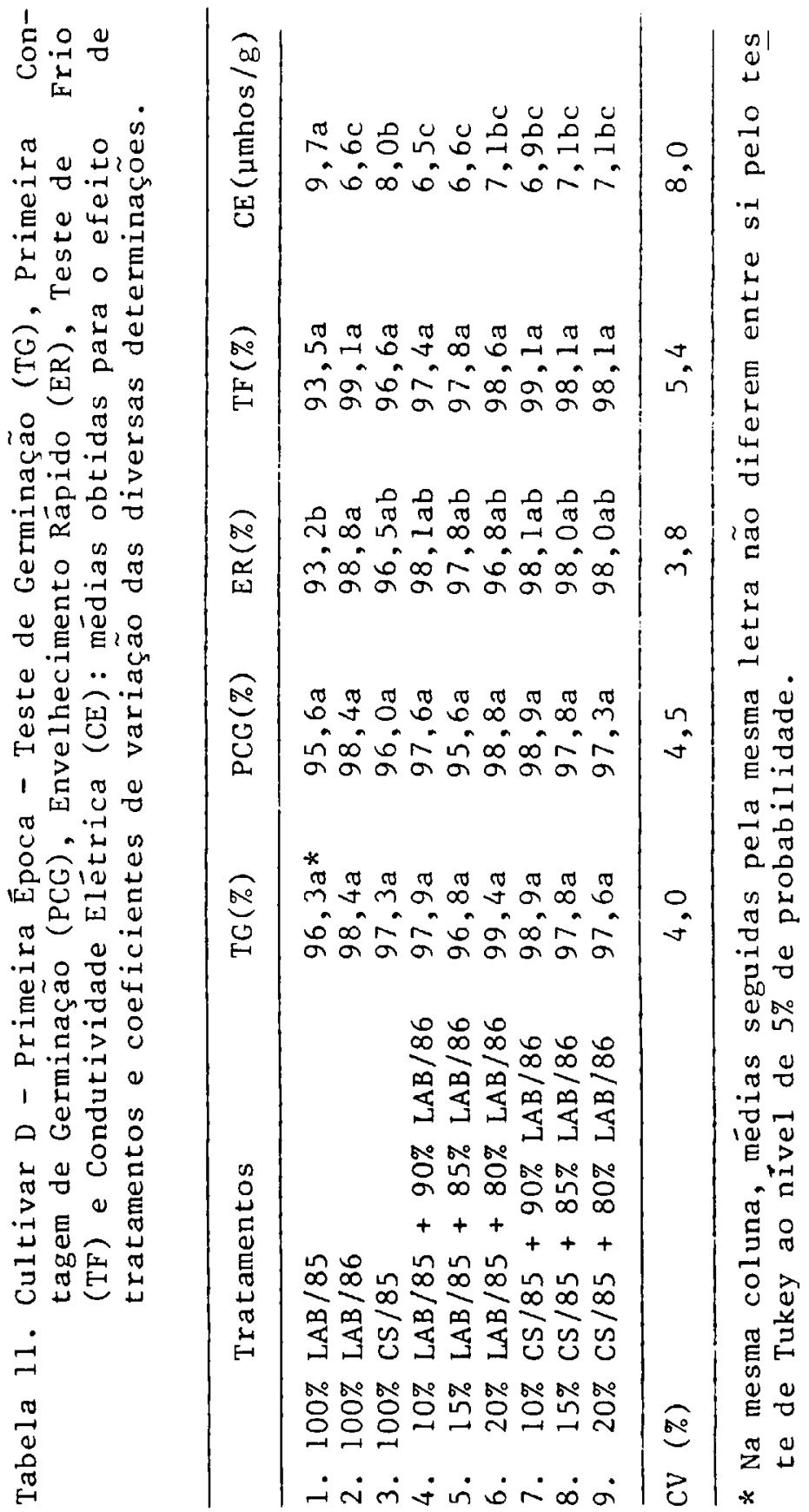




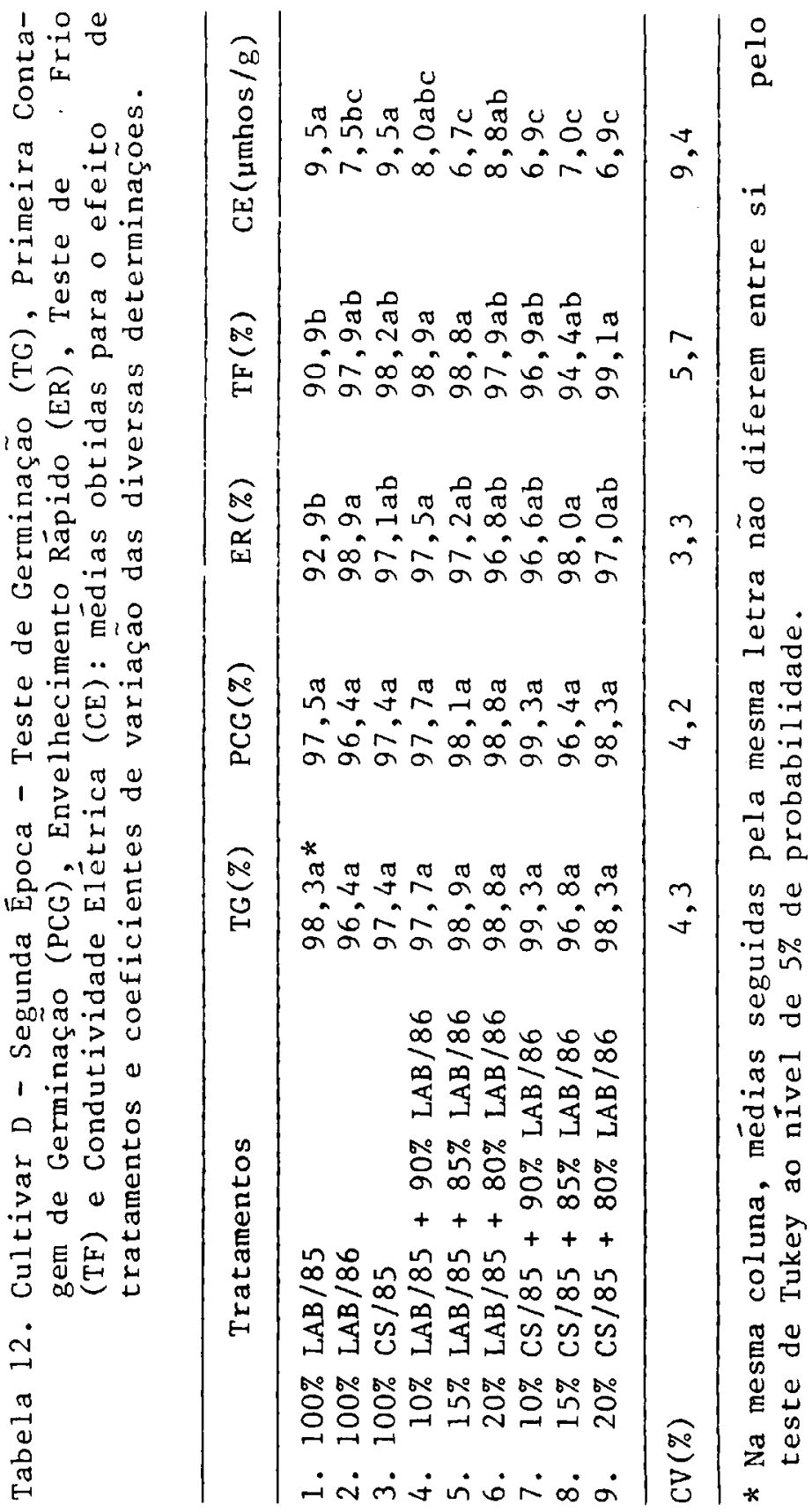


que a germinação não foi afetada quando se misturaram as sementes produzidas nas duas safras; $\bar{e}$ importante ressal tar que o material resultante da mistura de sementes das duas safras, nas proporções estudadas, não se diferenciou do material constituído exclusivamente por sementes novas (última safra). Apenas para o cultivar $C$, que apre sentava na ocasião da mistura, germinação inferior a $80 \overline{\%}$ para as sementes da primeira safra armazenadas em ambien te não controlado, foi observado uma tendência de queda de germinação à medida que se aumentava a proporção de sementes da safra anterior armazenadas em ambiente não controlado. Estes resultados demonstram a importância que se deve dar aos cuidados com o armazenamento, uma vez que o material mais velho que ficou armazenado em câmara seca, apresentou menor queda de germinação, ' não interferindo no material resultante da mistura de sementes das duas safras.

No que diz respeito à germinação os resultados obtidos no presente trabalho corroboram, parcialmente, com os resultados observados por CAMPOS (1979), CAMPOS(1980) e CICERO (1987), pois estes autores não observaram diferenças no comportamento entre o material constituído por $100 \%$ de sementes de milho produzidas na última safra e aquele constituído pela mistura de $10 \%$ de sementes do ano anterior com $90 \%$ de sementes da última safra.

Para os cultivares A, B e D, todos os tratamentos apresentaram sementes com germinação acima do valor exigido para comercialização (85\%); tal fato não ocorreu pa ra o cultivar $\mathrm{C}$, apenas para o tratamento constituídopor $100 \%$ de sementes da safra 1984/85 armazenadas em laboratório, nas duas épocas de realização dos testes.

Por outro lado, o vigor das sementes, avaliado pelos testes de primeira contagem de germinação, envelheci mento rápido, frio e condutividade elétrica, foi de maneira geral mais baixo para o material produzido na safra 1984/85 armazenado em ambiente não controlado (trata mento 1); entretanto, este material quando misturado com as sementes da safra 1985/86 não interferiu no vigor da mistura resultante para os cultivares $A$ e $D$ ao passo que 
para os cultivares $B$ e $C$ houve interferência no vigor apenas em algumas situações, quando se utilizaram, na mistura, $15 \%$ ou $20 \%$ de sementes da safra 1984/85 armazenadas em ambiente não controlado e $20 \%$ de sementes, da mesma safra armazenadas em câmara seca.

Deve-se destacar ainda que, na maioria das vezes, - material resultante da mistura de sementes das duas safras não se diferenciou, quanto ao vigor, do material constituído exclusivamente por sementes da ūltima safra (sementes novas). Estes resultados corroboram parcial mente com aqueles obtidos por CAMPOS (1979), CAMPOS (1980) e CICERO (1987).

\section{CONCLUSOES}

Nas condições do presente trabalho, a mistura de sementes de milho de duas safras subsequentes pode ser uma alternativa viável para o aproveitamento de sobras não comercializadas, pois a mistura das sementes mais ve lhas numa proporção de até $20 \%$ não afetou a germinação do material resultante; por outro lado, isto também ocorreu com vigor quando aquela proporção era de até $10 \%$.

\section{REFERENCIAS BIBLIOGRAFICAS}

BORGES, J.W.M. Efeitos de misturas de sementes de mitho ( $2 e a$ mays L.) de diferentes qualidades fisiologicas, sobre a germinação, vigor e produção. Lavras, 1983. 73p. (Mestrado-Escola Superior de Agricultura de Lavras).

BRASIL, Ministério da Agricultura, Secretaria Nacional de Defesa Agropecuäria. Regras para Análise de Sementes. Brasilia, 1980. 188p.

CAMPOS, M.S. Experimento de caldeamento. Sementes Agro ceres S.A./Departamento de Pesquisa, Santo Antonio da Platina, 1979. 7p. 
CAMPOS, M.S. Experimento de caldeamento. Sementes Agro ceres S.A./Departamento de Pesquisa, Santo Antonio da Platina, 1980. 19p.

CICERO, S.M. Mistura de lotes de diferentes idades e sua relação com a qualidade fisiológica e sanidade das sementes e desempenho das plantas de milho (Zea mays L.). Piracicaba, 1987. 119p. (Livre-Docência-Es cola Superior de Agricultura "Luiz de Queiroz").

DELOUCHE, J.C. Non-Uniformity in seed lots. In: SEED PROCESSOR'S CONFERENCE, Corvallis, 1975. Proceedings. Corvallis, Oregon State University, 1975. 12p.

KAHRE, L. Blended seed lots - Swedish experiences. In: ISTA CONGRESS, 16., Washington, 1971. 8p. (Preprint, 22).

MARCOS FILHO, J.; CICERO, S.M.; SILVA, W.R. Avaliagào da qualidade das sementes. Piracicaba, FEALQ, 1987. 230p.il.

VAUGHAN, C.E.; ALBRITTON, J.D.; BECK, J.M.; DOUGHERTY, G.M. Further studies on blending free flowing seeds bin flow control divices. Proceedings of the International Seed Testing Association, Zurich, 37(3):681$703,1972$.

Recebido para publicação em: 27.10 .88

Aprovado para publicaçăo em: 13.03.89 